\title{
А.Б. Груб'як ${ }^{1}$, В.О. Кощюбинський ${ }^{1}$, Л.В. Мохнацька ${ }^{1}$, В.В. Мокляк ${ }^{2}$, П.І. Колковський ${ }^{2}$, Г.І. Мудрик ${ }^{1}$ \\ СИНТЕЗ, СТРУКТУРА ТА ЕЛЕКТРОХІМІЧНІ ВЛАСТИВОСТІ УЛЬТРАДИСПЕРСНОГО АМОРФНОГО $\beta-\mathrm{FeOOH}$
}

\author{
${ }^{1}$ ДВНЗ «Прикарпатський національний університет імені Василя Стефаника» \\ вул. Шевченка, 57, Івано-Франківськ, 76025, Україна, E-mail: inst@pu.if.ua \\ ${ }^{2}$ Інститут металофізики ім. Г.В Курдюмова Національної академії наук України \\ бульвар Академіка Вернадського, 36, Київ, 03680, Україна, E-mail: metall@imp.kiev.иа
}

\begin{abstract}
Представлено спосіб отримання ультрадисперсного аморфного $\beta$-FеOОН відпалом $\mathrm{Fe}(\mathrm{OH})_{3}$, синтезованого гідротермальною обробкою розчину ичттрату заліза при $120{ }^{\circ} \mathrm{C}$ впродовж 5 год. 3 а допомогою рентгенівського аналізу та месбауерівської спектроскопії визначено фазовий склад та магнітну мікроструктуру гідрооксидів заліза, отриманих в результаті відпалу $\mathrm{Fe}(\mathrm{OH})_{3}$ в діапазоні $150-300{ }^{\circ} \mathrm{C}$, ma простежено механізми фазових перетворень $\mathrm{Fe}(\mathrm{OH})_{3} \rightarrow \beta-\mathrm{FeOOH}$. Встановлено, шзо після відпалу при $350{ }^{\circ} \mathrm{C}$ відбувається фазова трансформація $\beta$-FeOOH $\rightarrow \alpha-\mathrm{Fe}_{2} \mathrm{O}_{3}$. Досліджено електрохімічні властивості ультрадисперсного аморфного $\beta$-FеООН, отриманого відпалом при $300{ }^{\circ} \mathrm{C}$, за допомогою триелектродноі комірки у 3.5 М водному розчині КОН. Встановлено ефективність використання композиту $\beta$-FеООН / вуглецеві нанотрубки як активного електродного матеріалу у водних електролітах.
\end{abstract}

Ключові слова: ультрадисперсний аморфний $\beta$-FеООН, іон заліза, магнітна мікроструктура, фазова трансформація

\section{ВСТУП}

Інтерес до досліджень акагеніту $(\beta-\mathrm{FeOOH})$ викликаний широким спектром потенційних сфер його застосування як пігменту [1], фотокаталізатора [2] чи газового сенсора [3]. Водночас вивчення структурних властивостей $\beta$-FeOОН є передумовою запобігання процесам корозії сталей [4]. Перехід до ультрадисперсних розмірів частинок відкриває ще одну сферу практичного застосування $\beta$-FeOOH як ефектродного матеріалу електрохімічних джерел струму, зокрема, для суперконденсаторів [5]. При цьому, важливою вимогою для ефективного практичного застосування $є$ розуміння залежності електрофізичних властивостей матеріалу від умов його синтезу та структурноморфологічних характеристик.

Незважаючи на значну кількість наукових досліджень, до сьогодні відсутня загальноприйнята ідентифікація кристалічної та магнітної структур $\beta$-FeOOH, зокрема стосовно вибору сингонії кристалічної гратки, ідентифікації месбауерівських спектрів та числа парамагнітних компонент, необхідних для їх розшифровки [4]. Кристалічна структура $\beta$-FeOOH формується подвійними ланцюгами

() А.Б. Груб'як, В.О. Коцюбинський,

Л.В. Мохнацька, В.В. Мокляк,

П.І. Колковський, Г.І. Мудрик, 2016 октаедрів $\mathrm{Fe}(\mathrm{O}, \mathrm{OH})$, які утворюють тунельні порожнини. Проте, залежно від умов синтезу та наявності домішок, структура може бути тетрагональною чи моноклінною. Зокрема, у роботі [6] авторами пропонується тетрагональна структура 3 просторовою групою симетрії I4/m, в той час як у роботах $[7,8]$ запропонована моноклінна структура 3 групою симетрії I2/m.

Об'єктом вивчення залишається і магнітна мікроструктура $\beta$ - $\mathrm{FeOOH}$, який $\epsilon$ антиферомагнетиком 3 температурою Нееля $T_{\mathrm{N}}$ в діапазоні 250-300 K $[9,10]$. При $T<T_{\mathrm{N}}$ месбауерівський спектр антиферомагнітного $\beta-\mathrm{FeOOH}$ складається 3 двох секстетних компонент, що відповідають двом нееквівалентним положенням іонів $\mathrm{Fe}^{3+}$ в структурі. Поява третього секстету, спостережувана в ряді випадків, пов'язана із процесом переорієнтації спіну в результаті теплових коливань $[9,11]$. При температурі $T>T_{\mathrm{N}}$ месбауерівський спектр $\beta$ $\mathrm{FeOOH}$ апроксимується двома дублетними лініями із значеннями квадрупольного розщеплення $\quad 0.51-0.56 \mathrm{~mm} / \mathrm{c}$ та $0.92-0.96 \mathrm{~mm} / \mathrm{c} \quad \mathrm{i}$ співвідношенням інтенсивностей ліній - 40:60. У роботі [9] доведено, що дві дублетні лінії 
відповідають ядрам $\mathrm{Fe}^{57}$, які знаходяться в нееквівалентних октаедричних позиціях. На противагу цьому, у роботі [12] автор припускає, що месбауерівський спектр $\beta-\mathrm{FeOOH}$ при $T>T_{\mathrm{N}}$ апроксимується трьома дублетними лініями, причому інтенсивність двох із них завжди знаходиться в співвідношенні 2:1. Кількість дублетних компонент визначається числом можливих напрямків орієнтації градієнта електричного поля на ядрах $\mathrm{Fe}^{57}$ по відношенню до осі симетрії четвертого порядку.

Предметом постійного дослідження також залишаються процеси фазової трансформації $\beta$-FeOOH в гематит $\alpha-\mathrm{Fe}_{2} \mathrm{O}_{3}$, які типово відбуваються при термообробці на повітрі в діапазоні температур $300-400{ }^{\circ} \mathrm{C} \quad[9,13-18]$. Вивчення перебігу дисоціації $\beta$-FeOOH дозволить сформувати механізми активного впливу на зародкоутворення гідроокисних, оксидних та феритових фаз заліза [13].

Ефективність застосування $\beta$-FeOOH як електродного матеріалу суперконденсаторів зростає зі збільшенням його питомої площі поверхні в результаті збільшення ємності подвійного електричного шару та фарадеївської (окисно-відновної) ємності [5]. Використання ультрадисперсного $\beta-\mathrm{FeOOH}$ забезпечує можливість перебігу окисно-відновних реакцій за участю різних типів іонів $\left(\mathrm{H}^{+}, \mathrm{Na}^{+}, \mathrm{K}^{+} \mathrm{i} \mathrm{Li}^{+}\right)$. Як результат, значення питомої ємності може перевищити характеристики електродів на основі вуглецевих матеріалів, які працюють на принципі перезарядки подвійного електричного шару. Крім того, синтез ультра-дисперсного $\beta$ $\mathrm{FeOOH}$ не вимагає використання складних методів та високо-вартісних прекурсорів, проте суттєвим недоліком його використання в електрохімічних джерелах струму є низькі значення електропровідності, що призводить до зменшення псевдоємності.

Метою даної роботи стало дослідження структурних, магнітних характеристик й умов температурної стабільності структури ультрадисперсного аморфного $\beta-\mathrm{FeOOH}$ та вивчення його електрохімічних властивостей.

\section{СИНТЕЗ МАТЕРІАЛІВ ТА МЕТОДИ ДОСЛІДЖЕНЬ}

Синтез $\beta-\mathrm{FeOOH}$ передбачав декілька етапів. Перший етап включав взаємодію $0.3 \mathrm{M}$ водних розчинів $\mathrm{Fe}\left(\mathrm{NO}_{3}\right)_{3} \cdot 9 \mathrm{H}_{2} \mathrm{O}$ та $\mathrm{C}_{6} \mathrm{H}_{8} \mathrm{O}_{7} \cdot \mathrm{H}_{2} \mathrm{O}$ у молярному співвідношенні $1: 1$ при $55^{\circ} \mathrm{C}$ за умови безперервного перемішування. Утворений $0.3 \mathrm{M}$ колоїдний розчин цитрату заліза поміщали в гідротермальний реактор і піддавали обробці при $120^{\circ} \mathrm{C}$ протягом 5 год. Утворений осад промивали дистильованою водою до нейтрального значення $\mathrm{pH}$ водної суспензії. Промитий осад висушували на повітрі при $100{ }^{\circ} \mathrm{C}$. Отриманий порошок відпалювали при $150,200,250,300$ та $350{ }^{\circ} \mathrm{C}$ на повітрі впродовж 2 год із забором проб матеріалу при кожній температурі відпалу.

Багатошарові вуглецеві нанотрубки отримувалися методом хімічного осадження 3 газової фази в реакторі, що обертається [19]. Каталізатором слугувала оксидна композиція $\mathrm{Al}_{2} \mathrm{O}_{3}-\mathrm{MoO}_{3}-\mathrm{Fe}_{2} \mathrm{O}_{3}$. Джерелом вуглецю виступав пропілен, одержаний дегідратацією ізопропілового спирту.

Композит $\beta-\mathrm{FeOOH} /$ вуглецеві нанотрубки отримували внаслідок механічного змішування $\beta$-FеООН, синтезованого в результаті відпалу осаду при $300^{\circ} \mathrm{C}$, та вуглецевих нанотрубок. Масове співвідношення $\beta$-FeOOH: нанотрубки становило 20:1. Гомогенізація суміші здійснювалася за допомогою ультразвукового диспергатора протягом 30 хв в середовищі етанолу.

Дослідження фазового складу та кристалічної структури синтезованих матеріалів проводили за допомогою дифрактометра ДРОН-3.0 у випромінюванні мідного анода.

Месбауерівські дослідження виконано за допомогою спектрометра MS-1104Em 3 використанням ізотопа ${ }^{57} \mathrm{Co}$ в матриці $\mathrm{Cr} 3$ активністю $50 \mathrm{mKi}$. Калібрування ізомерних зсувів відбувалося відносно $\alpha-F e$. Месбауерівські спектри усіх зразків отримані при кімнатній температурі.

Вивчення електрохімічних властивостей ультрадисперсного $\beta-\mathrm{FeOOH}$ у водному електроліті проводилось за допомогою триелектродної комірки. Робочий електрод готувався шляхом запресування в нікелеву сітку суміші $\beta-\mathrm{FeOOH} /$ ацетиленова сажа / полівініліденфторид (розчин у етанолі) у масовому співвідношенні 75:20:5 (\%).Як протиелектрод використовували платиновий електрод, а електродом порівняння виступав хлор-срібний електрод. Електролітом слугував 3.5 М водний розчин $\mathrm{KOH}$. 


\section{РЕЗУЛЬТАТИ ТА ЇХ ОБГОВОРЕННЯ}

Відповідно до результатів рентгенівського аналізу, матеріал після висушування при $100^{\circ} \mathrm{C}$ перебуває в рентгеноаморфному стані (рис. 1). Відпал в температурному діапазоні $150-300{ }^{\circ} \mathrm{C}$ також не викликає формування кристалічних фаз. Дифрактограми вихідного матеріалу та зразків, отриманих після відпалу при $150-300^{\circ} \mathrm{C}$, характеризуються наявністю гало в області малих кутів, яке свідчить про наявність у досліджуваних матеріалах рентгеноаморфної складової.

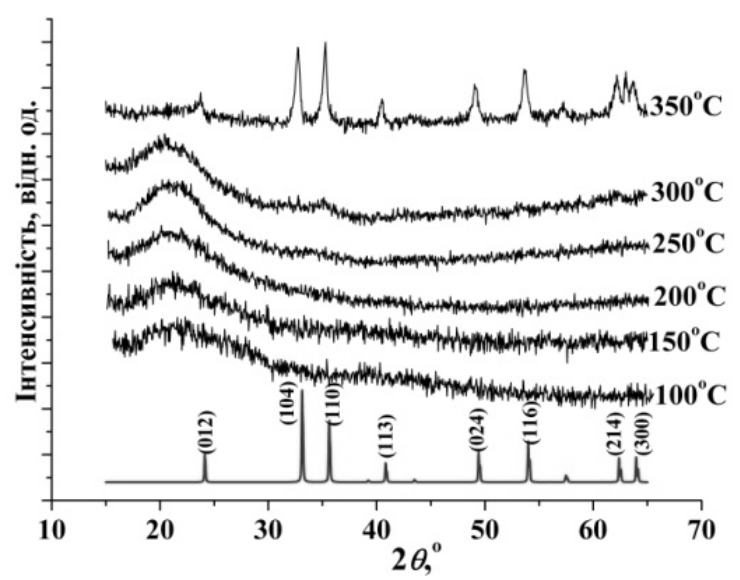

Рис. 1. Дифрактограми матеріалів, відпалених в температурному діапазоні $100-350{ }^{\circ} \mathrm{C}$, та еталонного (ICSD \#82137) $\alpha-\mathrm{Fe}_{2} \mathrm{O}_{3}$

Матеріал, отриманий відпалом при температурі $350^{\circ} \mathrm{C}, \epsilon$ монофазним гематитом $\alpha-\mathrm{Fe}_{2} \mathrm{O}_{3}$. Середній розмір областей когерентного розсіювання (ОКР) для $\alpha-\mathrm{Fe}_{2} \mathrm{O}_{3}$ розраховувався із застосуванням формули Шерpepa [20]: $<\mathrm{OKP}>=\lambda / \Delta(2 \theta) \cos \theta_{0}$, де $\lambda-$ довжина хвилі рентгенівських променів, $\Delta(2 \theta)$ - ширина піку на половині висоти, $\theta^{\circ}-$ кут дифракції. Розрахунки проводились на основі визначення ширини на половині висоти рефлексів (104), (110), (024) та (116). Отримані середні розміри ОКР для фази $\alpha-\mathrm{Fe}_{2} \mathrm{O}_{3}$ становлять $15.0 \pm 1.5$ нм.

Для визначення фазового складу та магнітної мікроструктури вихідного матеріалу, висушеного при $100^{\circ} \mathrm{C}$, та зразків, отриманих його відпалом при $150-300^{\circ} \mathrm{C}$, застосовувався метод месбауерівської спектроскопії.

Для вихідного матеріалу, отриманого після висушування осаду при $100^{\circ} \mathrm{C}$, месбауерівський спектр являє собою дублетну лінію, яка однозначно ідентифікується як результат резонансного поглинання $\gamma$-квантів на ядрах $\mathrm{Fe}^{3+}$ в парамагнітному стані (рис. 2). Спектр апроксимувався суперпозицією трьох дублетних компонент, параметри яких узагальнені в таблиці. Отримані значення ізомерного зсуву $(\delta)$ та квадрупольного розщеплення $(\Delta)$ узгоджуються з параметрами для фази $\mathrm{Fe}(\mathrm{OH})_{3}$ [21]. При цьому не виключається наявність у зразку пентагідрату цитрату заліза, оскільки зафіксовані параметри однієї із дублетних компонент відповідають літературним даним для $\mathrm{C}_{6} \mathrm{H}_{5} \mathrm{O}_{7} \mathrm{Fe} \cdot 5 \mathrm{H}_{2} \mathrm{O}$ [22].

Для зразків відпалених при 150 та $200{ }^{\circ} \mathrm{C}$ експериментальні спектри оптимально представлялися як суперпозиція двох дублетних компонент. Перша 3 них відповідає іонам $\mathrm{Fe}^{3+}$, стан яких не змінився в результаті відпалу. Друга компонента однозначно ідентифікується як результат резонансного поглинання $\gamma$ квантів на ядрах $\mathrm{Fe}^{2+}$. Таким чином, в температурному діапазоні $150-200{ }^{\circ} \mathrm{C}$ відбувається процес відновлення іонів заліза $\mathrm{Fe}^{3+} \rightarrow \mathrm{Fe}^{2+}$. Ймовірно, із підвищенням температури відпалу відбувається дегідратація матеріалу, причому цей процес відбувається просторово неоднорідно - області, де відбулось вилучення структурно зв'язаної води, співіснують 3 областями $\mathrm{Fe}(\mathrm{OH})_{3}$. Аналіз параметрів дублетних компонент спектрів зразків, отриманих відпалом при 150 та $200^{\circ} \mathrm{C}$, дозволив встановити ймовірну фазу, що відповідає іонам $\mathrm{Fe}^{2+}$. Згідно калібровки $\delta$ та $\Delta$ [21], іони $\mathrm{Fe}^{2+}$ перебувають у тетраедричному оточенні в структурі $\mathrm{Fe}(\mathrm{OH})_{2}$. Проте, враховуючи можливість наявності фази $\mathrm{C}_{6} \mathrm{H}_{5} \mathrm{O}_{7} \mathrm{Fe} \cdot 5 \mathrm{H}_{2} \mathrm{O}$, присутність в матеріалі іонів $\mathrm{Fe}^{2+}$ може бути пояснене переходом пентагідрату цитрату заліза(III) в оксалат заліза(II) при відпалі:

$$
\mathrm{C}_{6} \mathrm{H}_{5} \mathrm{O}_{7} \mathrm{Fe} \cdot 5 \mathrm{H}_{2} \mathrm{O} \rightarrow \mathrm{FeC}_{2} \mathrm{O}_{4} \cdot 2 \mathrm{H}_{2} \mathrm{O} \text { [23]. }
$$

Подальший відпал матеріалу обумовлює зникнення дублетної компоненти, що відповідає іонам $\mathrm{Fe}^{2+}$, а месбауерівські спектри матеріалів, відпалених при 250 та $300{ }^{\circ} \mathrm{C}$, характеризується наявністю лінії парамагнітної складової, яка відповідає резонансному поглинанню $\gamma$-квантів ядрами $\mathrm{Fe}^{3+}$. Відсутність в матеріалі іонів $\mathrm{Fe}^{2+}$ після відпалу при $250{ }^{\circ} \mathrm{C}$, ймовірно, зумовлюється термодеструкцією органічних сполук i, як наслідок, перебігом 
процесу окиснення $\mathrm{Fe}^{2+} \rightarrow \mathrm{Fe}^{3+}$ за однією із наступних реакцій:

$$
\begin{aligned}
& \mathrm{Fe}^{2+}+\mathrm{O}_{2} \rightarrow \mathrm{Fe}^{3+}+\mathrm{O}_{2}^{-} \\
& 2 \mathrm{Fe}^{2+}+\mathrm{O}_{2}+2 \mathrm{H}^{+} \rightarrow 2 \mathrm{Fe}^{3+}+\mathrm{H}_{2} \mathrm{O}_{2} \\
& 2 \mathrm{O}_{2}^{-}+2 \mathrm{H}^{+} \rightarrow \mathrm{H}_{2} \mathrm{O}_{2}+\mathrm{O}_{2} \\
& \mathrm{Fe}^{2+}+\mathrm{H}_{2} \mathrm{O}_{2} \rightarrow \mathrm{Fe}^{3+}+\mathrm{OH}^{*}+\mathrm{OH}^{-}
\end{aligned}
$$

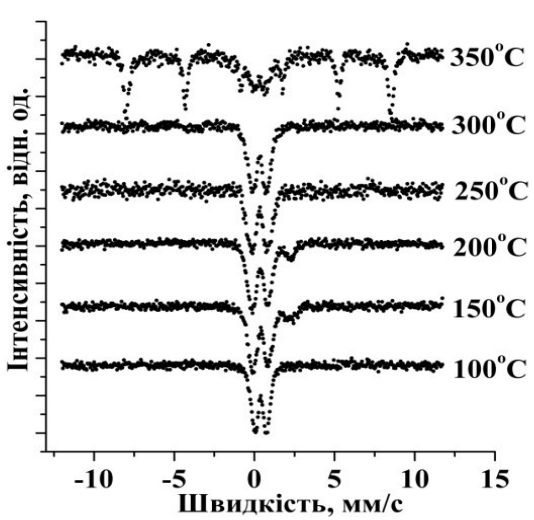

Рис. 2. Месбауерівські спектри матеріалів, отриманих термообробкою вихідного осаду

\begin{tabular}{|c|c|c|c|c|c|}
\hline$T,{ }^{\circ} \mathbf{C}$ & Фaзa & $\delta, \mathbf{M M} / \mathbf{c}$ & $\Delta, \mathbf{M M} / \mathbf{c}$ & $\omega, \mathbf{M M} / \mathbf{c}$ & $S, \%$ \\
\hline \multirow{3}{*}{100} & \multirow{3}{*}{$\mathrm{Fe}(\mathrm{OH})_{3} / \mathrm{C}_{6} \mathrm{H}_{5} \mathrm{O}_{7} \mathrm{Fe} \cdot 5 \mathrm{H}_{2} \mathrm{O}$} & 0.38 & 0.93 & 0.51 & 60 \\
\hline & & 0.44 & 0.63 & 0.37 & 18 \\
\hline & & 0.37 & 0.49 & 0.35 & 22 \\
\hline \multirow{2}{*}{150} & $\mathrm{Fe}(\mathrm{OH})_{3} / \mathrm{C}_{6} \mathrm{H}_{5} \mathrm{O}_{7} \mathrm{Fe} \cdot 5 \mathrm{H}_{2} \mathrm{O}$ & 0.39 & 0.96 & 0.61 & 67 \\
\hline & $\mathrm{Fe}(\mathrm{OH})_{2} / \mathrm{FeC}_{2} \mathrm{O}_{4} \cdot 2 \mathrm{H}_{2} \mathrm{O}$ & 0.92 & 2.26 & 1.42 & 33 \\
\hline \multirow{2}{*}{200} & $\mathrm{Fe}(\mathrm{OH})_{3} / \mathrm{C}_{6} \mathrm{H}_{5} \mathrm{O}_{7} \mathrm{Fe} \cdot 5 \mathrm{H}_{2} \mathrm{O}$ & 0.38 & 0.98 & 0.67 & 81 \\
\hline & $\mathrm{Fe}(\mathrm{OH})_{2} / \mathrm{FeC}_{2} \mathrm{O}_{4} \cdot 2 \mathrm{H}_{2} \mathrm{O}$ & 0.91 & 2.63 & 0.64 & 19 \\
\hline \multirow{2}{*}{250} & $\beta-\mathrm{FeOOH}$ & 0.33 & 1.14 & 0.69 & 87 \\
\hline & & 0.32 & 0.61 & 0.33 & 13 \\
\hline \multirow{2}{*}{300} & $\beta_{-} \mathrm{Fe} \cap O H$ & 0.32 & 0.97 & 0.62 & 90 \\
\hline & p-геUणн & 0.34 & 0.51 & 0.24 & 10 \\
\hline 350 & $\alpha-\mathrm{Fe}_{2} \mathrm{O}_{3}$ & 0.33 & 0.76 & 0.77 & 32 \\
\hline
\end{tabular}
в температурному діапазоні $100-350{ }^{\circ} \mathrm{C}$

Таблиця. Параметри дублетних компонент месбауерівських спектрів зразків, отриманих при різних температурах відпалу

Примітка: $\delta$ - ізомерний зсув, $\Delta$ - квадрупольне розщеплення, $\omega$ - ширина лінії, $S$ - інтегральна інтенсивність

Експериментальні парамагнітні складові спектрів для зразків, отриманих відпалом при 250 та $300{ }^{\circ} \mathrm{C}$, апроксимуються суперпозицією двох дублетних компонент 3 близькими значеннями $\delta$ та відмінними значеннями $\Delta$. Враховуючи діаграми фазових переходів гідроксидів заліза при нагріванні на повітрі [24], калібровки параметрів месбауерівських спектрів [21] та результати рентгенівського аналізу (рис. 1), матеріали, відпалені при 250 та $300{ }^{\circ} \mathrm{C}$, можна ідентифікувати як ультрадисперсний аморфний $\beta$-FeOOH.

Наявність у спектрі двох дублетних компонент 3 різними значеннями квадрупольного розщеплення пояснюється відмінностями в ближньому оточенні ядер ${ }^{57} \mathrm{Fe}$, які знаходяться у нееквівалентних позиціях в структурі $\beta$-FeOОН. Авторами $[9,25,26]$ поставлено у відповідність двом дублетним компонентам месбауерівських спектрів $\beta-\mathrm{FeOOH}$ розташуванням іонів $\mathrm{Fe}^{3+}$ в позиціях $\mathrm{FeO}_{3}(\mathrm{OH})_{3}$ і $\mathrm{FeO}_{2}(\mathrm{OH})_{4}$. В той час у роботах $[7,8,27]$ авторами для випадку тетрагональної структури $\beta$ $\mathrm{FeOOH}$ припускається наявність лише однієї координації - $\mathrm{FeO}_{3}(\mathrm{OH})_{3}$. При розгляді моноклінної структури $\beta$-FеООН месбауерівський спектр при $T>T_{\mathrm{N}}$ апроксимується двома дублентими лініями, які також відповідають двом нееквівалентним позиціям іонів $\mathrm{Fe}^{3+}$ [7,28-30]. Проте, в такому випадку постає питання про можливість невпорядкованого заповнення іонами $\mathrm{Fe}^{3+}$ порожнин, що не дозволяє виділити дві окремі катіонні позиції.

Подальший відпал матеріалу при $350{ }^{\circ} \mathrm{C}$ викликає зменшення дублетної складової месбауерівського спектра, параметри якої 
відповідають іонам $\mathrm{Fe}^{3+}$, і появу секстетної лінії, для якої ефективне магнітне поле $H_{\text {еф }}$ на ядрі ${ }^{57} \mathrm{Fe}$ становить $512 \mathrm{\kappa E}$, а $\delta=0.37 \mathrm{мm} / \mathrm{c}$ та $\Delta=-0.20 \mathrm{Mm} / \mathrm{c}$ (рис. 2). Близький набір параметрів $\left(H_{\text {eф }}=515 \mathrm{\kappa E}, \quad \delta=0.38 \mathrm{mм} / \mathrm{c}, \quad \Delta=-0.24 \mathrm{~mm} / \mathrm{c}\right)$ характерний для гематиту $\alpha-\mathrm{Fe}_{2} \mathrm{O}_{3}[31]$. Таким чином, секстетна складова месбауерівського спектра зразка, отриманого відпалом при $350^{\circ} \mathrm{C}, \epsilon$ результатом резонансного поглинання $\gamma$-квантів ядрами іонів $\mathrm{Fe}^{3+}$ в магнітновпорядкованому стані в частинках $\alpha-\mathrm{Fe}_{2} \mathrm{O}_{3}$, що однозначно узгоджується 3 результатами ренгенівського аналізу для цього зразка (рис. 1).

Таким чином, гідротермальна обробка розчину цитрату заліза при $120^{\circ} \mathrm{C}$ впродовж 5 год зумовлюе формування гідроксидних сполук $\mathrm{Fe}^{3+}$. Подальший відпал в діапазоні $150-350{ }^{\circ} \mathrm{C}$ спричиняс структурні трансформації матеріалу зміною валентності заліза та фазового складу гідроксидних сполук. В температурному вікні $250-300{ }^{\circ} \mathrm{C}$ утворюється стабільна ультрадисперсна аморфна фаза $\beta$-FeOOH, електрохімічні властивості якої вивчалися на наступному етапі роботи.

Вольтамперограми електроду на основі ультрадисперсного $\beta$ - $\mathrm{FeOOH}$ отримувалися із застосуванням триелектродної комірки в діапазоні напруг [-0.85 B; -0.1 В] при різних швидкостях сканування (1-50 мB/c) (рис. 3). Встановлено, що формування ємності для
$\beta$-FеООН у електроліті $3.5 \mathrm{M} \mathrm{KOH} \mathrm{відбувається}$ в результаті утворення поверхневого електричного шару (ПЕШ), а також, ймовірно, за рахунок окисно-відновних реакцій $\mathrm{Fe}^{3+} \leftrightarrow \mathrm{Fe}^{2+}$. Обчислені значення питомих ємностей розряду та заряду представлені на рис. 3 б. Спостерігається експоненційне зменшення питомої ємності розряду від 49 до 4 Ф/г при зростанні швидкості сканування від 1 до $50 \mathrm{MB} / \mathrm{c}$, що відповідає максимуму кулонівської ефективності при швидкості сканування $5 \mathrm{mB} / \mathrm{c}$. На вольтамперограмах спостерігається нечітко виражений максимум, який зсувається в бік негативних потенціалів зі зростанням швидкості сканування.

За характером вольтамперограми відповідають перебігу в системі необоротних окисно-відновних реакцій - пік, що відповідає анодному процесу, практично відсутній, спостерігається зсув катодних піків при зміні швидкості сканування.

Для збільшення електронної та іонної провідності в електродному матеріалі можливе використання гібридних матеріалів - композитів гідрооксиду заліза та вуглецевих наноматеріалів, зокрема, вуглецевих нанотрубок [32]. Вольтамперограми електродів на основі композиту $\beta-\mathrm{FeOOH} /$ вуглецеві нанотрубки характеризуються наявністю максимуму на катодній вітці в околі $-0.7 \div-0.6$ В (рис. 4).

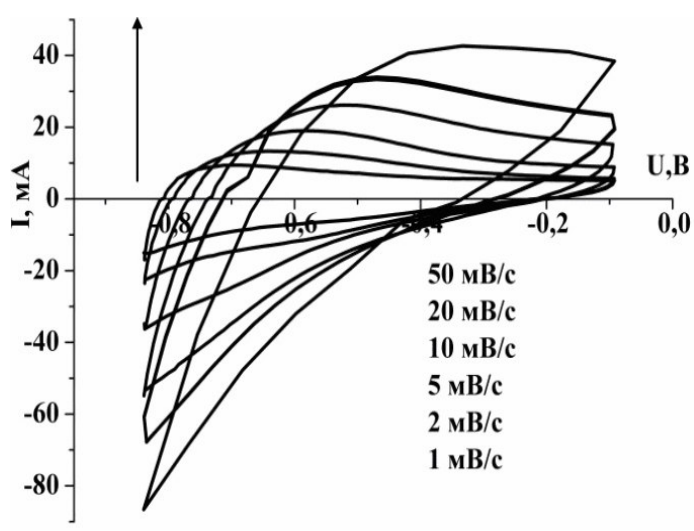

$a$

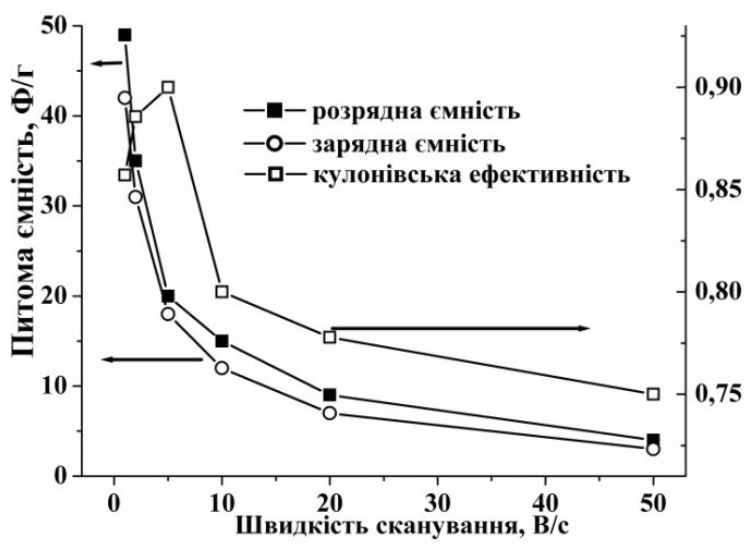

$\sigma$

Рис. 3. Циклічні вольтамперограми електрода на основі ультрадисперсного $\beta$-FеООН при різних швидкостях сканування (a) і розраховані на їх основі значення питомих ємностей заряд/розряду та кулонівські ефективності цих процесів (б) 


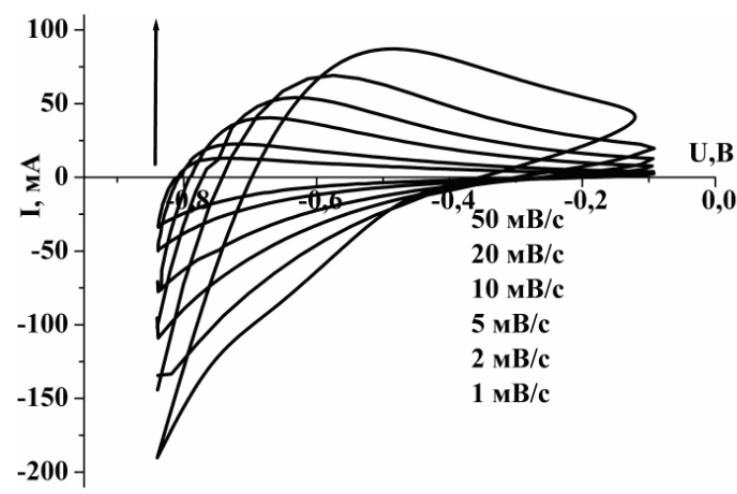

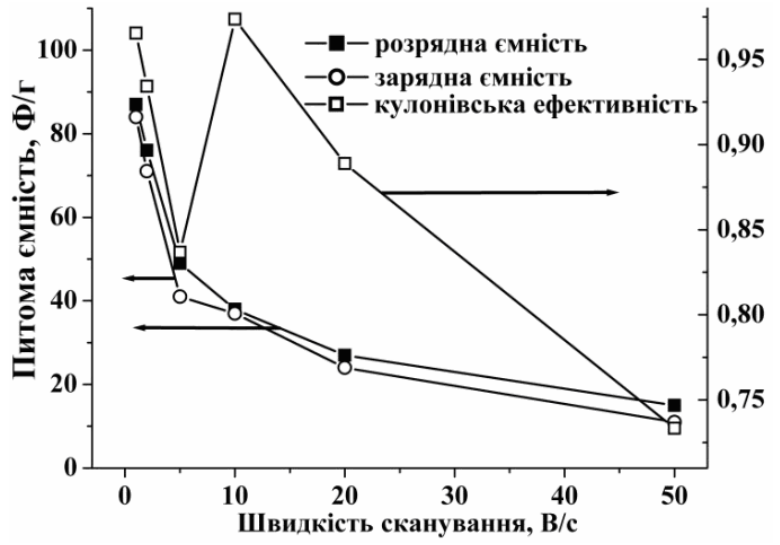

6

Рис. 4. Циклічні вольтамперограми електрода на основі композиту ультрадисперсний $\beta$-FеООН / вуглецеві нанотрубки при різних швидкостях сканування $(a)$ і розраховані на їх основі значення питомих ємностей заряду і розряду та кулонівські ефективності цих процесів (б)

Обчислені питомі ємності розряду для композиту $\beta-\mathrm{FeOOH} /$ вуглецеві нанотрубки $\epsilon$ порівняно вищими, ніж для чистого $\beta-\mathrm{FeOOH}, \mathrm{i}$ змінюються в межах 87-15 Ф/Г при зростанні швидкості сканування від 1 до $50 \mathrm{MB} / \mathrm{c}$. Необоротність електрохімічних процесів спостерігається і у випадку застосування композиту.

\section{ВИСНОВКИ}

Гідротермальною обробкою розчину цитрату заліза при $120^{\circ} \mathrm{C}$ впродовж 5 год отримано фазу $\mathrm{Fe}(\mathrm{OH})_{3}$. Простежено механізм формування стабільної ультрадисперсної аморфної фази $\beta$-FeOOH в результаті відпалу
$\mathrm{Fe}(\mathrm{OH})_{3}$ в діапазоні $150-300{ }^{\circ} \mathrm{C}$. Виявлено зміни магнітної мікроструктури матеріалів в процесі відпалу та ідентифіковані реакції, які їх спричиняють. Встановлено, що після відпалу при $350{ }^{\circ} \mathrm{C}$ відбувається фазова трансформація $\beta-\mathrm{FeOOH} \rightarrow \alpha-\mathrm{Fe}_{2} \mathrm{O}_{3}$ : розмір ОКР для фази гематиту становить $15.0 \pm 1.5$ нм. Вивчено електрохімічні властивості ультрадисперсного аморфного $\beta-\mathrm{FeOOH}$ за допомогою триелектродної комірки у $3.5 \mathrm{M}$ водному розчині $\mathrm{KOH}$ та встановлено ефективність вико ристання композитних сполук $\beta$-FeOOH / вуглецеві нанотрубки як активного електродного матеріалу у водних електролітах.

\section{Синтез, структура и электрохимические свойства ультрадисперсного аморфного $\beta$-FеOOH}

\section{А.Б. Грубьяк, В.О. Коцюбинский, Л.В. Мохнацкая, В.В. Мокляк, П.И. Колковский, Г.И. Мудрик}

ГВУЗ «Прикарпатский национальный университет имени Василия Стефаника» ул. Шевченко, 57, Ивано-Франковск, 76025, Украина, inst@pu.if.uа

Институт металлофизики им. Г.В Курдюмова Национальной академии наук Украины бульвар Академика Вернадского, 36, Киев, 03680, Украина, теtall@imp.kiev.иа

Представлен способ получения ультрадисперсного аморфного $\beta$-FеОН отюсигом $\mathrm{Fe}(\mathrm{OH})_{3}$, синтезированного гидротермальной обработкой раствора изитрата железа при $120{ }^{\circ} \mathrm{C}$ в течение 5 часов. $C$ помощью рентгеновского анализа и мессбауэровской спектроскопии определены фазовый состав и магнитная микроструктура гидрооксидов железа, полученных в результате отжига $\mathrm{Fe}(\mathrm{OH})_{3}$ в диапазоне 150-300 ${ }^{\circ} \mathrm{C}$, и прослежены механизмы фазовых превращений $\mathrm{Fe}(\mathrm{OH})_{3} \rightarrow \beta$-FeOOH. Установлено, что после отжига при $350{ }^{\circ} \mathrm{C}$ происходит фазовая трансформация $\beta$-FeOOH $\rightarrow \alpha-\mathrm{Fe}_{2} \mathrm{O}_{3}$. Исследованы электрохимические свойства ультрадисперсного аморфного $\beta$-FеООН, полученного отжсиом при $300{ }^{\circ} \mathrm{C}$, $\mathrm{c}$ помощью трехэлектродной ячейки в $3.5 \mathrm{M}$ водном растворе КОН. Установлена эфрфективность 
использования композита $\beta$-FеООН/углеродные нанотрубки в качестве активного электродного материала в водных электролитах.

Ключевые слова: ультрадисперсный аморфный $\beta$-FеООН, ион железа, магнитная микроструктура, фазовая трансформачия

\title{
Synthesis, structure and electrochemical properties of ultrafine amorphous $\beta-\mathrm{FeOOH}$
}

\author{
A.B. Hrubiak, V.O. Kotsyubynsky, L.V. Mokhnatska, V.V. Moklyak, P.I. Kolkovsky, G.I. Mudryk \\ Vasyl Stefanyk Precarpathian National University \\ 57 Shevchenko Str., Ivano-Frankivsk, 76025,Ukraine, inst@pu.if.ua \\ Institute of Metal Physics of National Academy of Sciences of Ukraine \\ 36 Akademician Vernadsky Blvd., Kyiv,03680,Ukraine, metall@imp.kiev.ua
}

The aim of the article is to find relationships between synthesis conditions and phase composition, magnetic microstructure and electrochemical properties of ultrafine amorphous iron hydroxide phases obtained by iron citrate sol hydrothermal treatment. The sol of iron citrate was formed by mixing of $0.3 \mathrm{M}$ iron nitrate aqueous solutions with citric acid. Hydrothermal treatment of iron citrate was carried out at $120^{\circ} \mathrm{C}$ for 5 hours with the next annealing of precipitation at 150, 200, 250, 300 and $350^{\circ} \mathrm{C}$ in air for 2 hours. X-ray analysis and Mössbauer spectroscopy were used for phase composition and magnetic microstructure control of the obtained iron hydroxides. All the synthesized materials were X-ray amorphous so the Mössbauer spectroscopy was used for phases recognition. In has been determined that the hydrothermal treatment of iron citrate solution at $120^{\circ} \mathrm{C}$ for 5 hours leads to $\mathrm{Fe}(\mathrm{OH})_{3}$ formation. The annealing in the temperature range of $150-200^{\circ} \mathrm{C}$ causes the reduction of iron $\mathrm{Fe}^{3+} \rightarrow \mathrm{Fe}^{2+}$ as a result of material dehydration. Under this condition the composite $\mathrm{Fe}(\mathrm{OH})_{3} / \mathrm{Fe}(\mathrm{OH})_{2}$ was formed with the pentahydrate iron citrate $\mathrm{C}_{6} \mathrm{H}_{5} \mathrm{O}_{7} \mathrm{Fe} \cdot 5 \mathrm{H}_{2} \mathrm{O}$ and iron oxalate $\mathrm{FeC}_{2} \mathrm{O}_{4} \cdot 2 \mathrm{H}_{2} \mathrm{O}$ presence. Amorphous ultrafine $\beta$-FeOOH was obtained after $\mathrm{Fe}(\mathrm{OH})_{3}$ annealing at $250{ }^{\circ} \mathrm{C}$ for 2 hours. It has been found that after annealing at $350{ }^{\circ} \mathrm{C}$ phase transformation of $\beta-\mathrm{FeOOH} \rightarrow \alpha-\mathrm{Fe}_{2} \mathrm{O}_{3}$ has occurred. The sizes of coherent scattering regions for $\alpha-\mathrm{Fe}_{2} \mathrm{O}_{3}$ phase are about $15.0 \pm 1.5 \mathrm{~nm}$. The electrochemical properties of ultrafine amorphous $\beta$-FeOOH and composite $\beta$-FeOOH/carbon nanotubes in 3.5M KOH aqueous solution were studied. The efficiency of $\beta-\mathrm{FeOOH/carbon} \mathrm{nanotube} \mathrm{as} \mathrm{potential} \mathrm{electrode} \mathrm{material} \mathrm{for} \mathrm{supercapacitor} \mathrm{was} \mathrm{shown.}$

Keywords: amorphous ultrafine $\beta-\mathrm{FeOOH}$, ion of iron, magnetic microstructure, phase transformation

\section{ЛIТЕРАТУРА}

1. Xiong W., Xiangying C., Lisheng $G$. et al. Synthesis of $\beta-\mathrm{FeOOH}$ and $\alpha-\mathrm{Fe}_{2} \mathrm{O}_{3}$ nanorods and electrochemical properties of $\beta-\mathrm{FeOOH} / /$ J. Mater. Chem. - 2004. - V. 14. - P. 905-907.

2. Zhihui X., Jianru L., Lixiang Z. Template-Free Hydrothermal Synthesis of $\beta$-FeOOH Nanorods and Their Catalytic Activity in the Degradation of Methyl Orange by a Photo-Fenton-Like Process // Open Journal of Inorganic NonMetallic Materials. - 2013. - V. 3, N 4. - P. 58-65.

3. Frausto C.T., Garcia A.A. Zinc and Pyrrole-added Akaganeite ( $\beta$-FeOOH) Films by Ultrasonic Spray Pyrolisis Assessed as Propane Sensors // Sensors and Transducers. - 2012. - V. 146, N 11. - P. 170-181.

4. Garcia K.E., Barrero C.A., Morales A.L., Greneche J.-M. Magnetic structure of synthetic akaganeite: A review of Mössbauer data // Rev. Fac. Ing. Univ. Antioquia. - 2009. - N 49. - P. 185-191.

5. Amine K., Yasuda H., Yamachi M. $\beta-\mathrm{FeOOH}$, a new positive electrode material for lithium secondary batteries // J. Power Sources. - 1999. - V. 81-82, N 1-2. - P. 221-223.

6. Mackay A.L. B-Ferric Oxyhydroxide-Akaganéite // Mineral Mag. - 1962. - V. 33, N 259. - P. 270-280.

7. Post J.E., Buchwald V.F. Crystal structure refinement of akaganeite // Am. Mineral. - 1991. - V. 76, N 1-2. - P. $272-277$.

8. Post J.E., Heaney P.J., Von Dreele R.B., Hanson J.C. Neutron and temperature-resolved synchrotron X-ray powder diffraction study of akaganéite // Am. Mineral. - 2003. - V. 88, N 5. - P. 782-788.

9. Chambaere D.G., De Grave E. On the influence of the dual iron co-ordination on the hyperfine field in $\beta$-FeOOH // Journal of Magnetic and Magnetism Materials. - 1984. - V. 44. - P. 349-352.

10. Pollard R.J., Cardile C.M., Lewis D.G., Brown L.J. Characterization of FeOOH Polymorphs and Ferrihydrite Using Low-Temperature, Applied-Field, Mössbauer Spectroscopy // Clay Miner. - 1992. - V. 27. - P. 57-71. 
11. Pankhurst, Q.A., Pollard R.J. Mossbauer-spectra of antiferromagnetic powders in applied fields // J. Phys.: Condens. Matter. - 1990. - V. 2, N 35. - P. 7329-7337.

12. Rezel D., Genin J.M.R. The substitution of chloride ions to $\mathrm{OH}^{-}$-ions in the akaganeite beta ferric oxyhydroxide studied by Mössbauer effect // Hyperfine Interact. - 1990. - V. 57, N 1. - P. 2067-2076.

13. Dezsi I., Keszthelyi L., Kutgawczuk D. et al. Mössbauer Study of $\beta$ - and $\delta$-FeOOH and their Disintegration Products // Phys. Stat. Sol. - 1967. -V. 22, N 2. - P. 617-629.

14. Braun H., Gallagher K.J. $\beta-\mathrm{Fe}_{2} \mathrm{O}_{3}$, a New Structural Form of Iron (III) Oxide // Nature Phys. Sci. - 1972. - V. 240. P. 13-14.

15. Howe A.T., Gallagher K.J. Mössbauer studies in the colloid system $\beta-\mathrm{FeOOH}-\beta-\mathrm{Fe}_{2} \mathrm{O}_{3}$ : structures and dehydration mechanism // Journal of the Chemical Society, Faraday Transactions 1: Physical Chemistry in Condensed Phases. 1975. - V. 71. - P. 22-34.

16. Gonzalez-Calbet J.M., Alario Franco M.A. A thermogravimetric and electron microscopy study of the decomposition of akaganeite // Thermochim. Acta. - 1982. - V. 58, N 1. - P. 45-51.

17. Chambaere D.G., De Grave E. The $\beta-\mathrm{FeOOH}$ to $\alpha-\mathrm{Fe}_{2} \mathrm{O}_{3}$ phase transformation: Structural and magnetic phenomena // Phys. Chem. Miner. - 1985. - V. 12, N 3. - P. 176-184.

18. Nagai N., Hosoito N., Kiyama M. et al. The Thermal Decomposition Intermediate Product of P-FeO(OH) // Ferrites: Proc. of the International Conference (Sept.-Oct., 1980, Japan). - P. 247.

19. Revo S., Alekseev A., Ivanenko E. et al. Structure, tribotechnical, and thermophysical characterristics of the fluoroplastic carbon nanotubes material // Nanoscale Res. Lett. - 2014. - V. 9, N 1. - P. 1-4.

20. Гинье A. Рентгенография кристаллов. Теория и практика. - Москва: Наука, 1961. - 604 с.

21. Sei J.O., Cook D.C., Townsend H.E. Characterization of Iron Oxides Commonly Formed as Corrosion Products on Steel // Hyperfine Interact. - 1998. - V. 112, N 1-4. - P. 59-66.

22. Bassi P.S., Randhawa B.S., Jamwal H.S. Mossbauer study of the thermal decomposition of iron(III) citrate pentahydrate // J. Therm. Anal. - 1984. - V. 29, N 3. - P. 439-444.

23. Buchanan D.N.E. Mossbauer and spectroscopy of radiolytic photolytic effects on ferric citrate // J. Inorg. Nucl. Chem. - 1970. - V. 32, N 11. - P. 3531-3533.

24. Bernal J.D., Dasgupta D.R., Mackay A.L. The Oxides and Hydroxides of Iron and Their Structural Inter-Relationships // Clay Miner. - 1959. - V. 4, N 21. - P. 15-30.

25. Chambaere D.G., De Grave E., Vanleerberghe R.L., Vandenberghe R.E. The electric field gradient at the iron sites in $\beta$-FeOOH // Hyperfine Interact. - 1984. - V. 20, N 4. - P. 249-262.

26. Chambaere D.G., De Grave E. A study of the non-stoichiometrical halogen and water content of $\beta$-FeOOH // Phys. Stat. Sol. - 1984. - V. 83. - P. 93-102.

27. Stahl K., Nielsen K., Jiang J. et al. On the akaganeite crystal structure, phase transformations and possible role in postexcavational corrosion of iron artifacts // Corros. Sci. - 2003. - V. 45, N 11. - P. 2563-2575.

28. Barrero C.A., Garcia K. E., Morales A.L. et al. New analysis of the Mössbauer spectra of akaganeite // J. Phys.: Condens. Matter. - 2006. - V. 18, N 29. - P. 6827-6840.

29. Garcia K.E., Morales A.L., Barrero C.A., Greneche J.M. Characterization of akaganeite synthesized in the presence of $\mathrm{Al}^{3+}, \mathrm{Cr}^{3+}$, and $\mathrm{Cu}^{2+}$ ions and urea // Mater. Chem. Phys. - 2008. - V. 112, N 1. - P. 120-126.

30. Garcia K.E., Morales A.L., Barrero C.A. et al. Magnetic and crystal structure refinement in akaganeite nanoparticle // Physica B. - 2004. - V. 354, N 1-4. - P. 187-190.

31. Kuzmann E., Nagy S., Vertes A. Critical Review Of Analytical Applications Of Mossbauer Spectroscopy Illustrated By Mineralogical And Geological Examples // Pure Appl. Chem. - 2003. - V. 75, N 6. - P. 801-858.

32. Long C., Jiang L., Wei T. al. High-performance asymmetric supercapacitors with lithium intercalation reaction using metal oxide-based composites as electrode materials // J. Mater. Chem. A. - 2014. - V. 2, N 39. - P. 16678-16686.

\section{REFERENCES}

1. Xiong W., Xiangying C., Lisheng G., Huagui Z., Mingrong J., Chenming T., Tao S., Zude Z. Synthesis of $\beta$-FeOOH and $\alpha-\mathrm{Fe}_{2} \mathrm{O}_{3}$ nanorods and electrochemical properties of $\beta$-FeOOH. J. Mater. Chem. 2004. 14: 905.

2. Zhihui X., Jianru L., Lixiang Z. Template-Free Hydrothermal Synthesis of $\beta$-FeOOH Nanorods and Their Catalytic Activity in the Degradation of Methyl Orange by a Photo-Fenton-Like Process. Open Journal of Inorganic NonMetallic Materials. 2013. 3(4): 58.

3. Frausto C.T., Garcia A.A. Zinc and Pyrrole-added Akaganeite $(\beta-\mathrm{FeOOH})$ Films by Ultrasonic Spray Pyrolisis Assessed as Propane Sensors. Sensors and Transducers. 2012. 146(11): 170.

4. Garcia K. E., Barrero C.A., Morales A.L., Greneche J.-M. Magnetic structure of synthetic akaganeite: A review of Mössbauer data. Rev. Fac. Ing. Univ. Antioquia. 2009. (49): 185. 
5. Amine K., Yasuda H., Yamachi M. $\beta$-FeOOH, a new positive electrode material for lithium secondary batteries. $J$. Power Sources. 1999. 81-82(1-2): 221.

6. Mackay A.L. $\beta$-Ferric Oxyhydroxide-Akaganéite. Mineral Mag. 1962. 33(259): 270.

7. Post J. E., Buchwald V. F. Crystal structure refinement of akaganeite. Am. Mineral. 1991. 76(1-2): 272.

8. Post J.E., Heaney P.J., Von Dreele R.B., Hanson J.C. Neutron and temperature-resolved synchrotron X-ray powder diffraction study of akaganéite. Am. Mineral. 2003. 88(5): 782.

9. Chambaere D.G., De Grave E. On the influence of the dual iron co-ordination on the hyperfine field in $\beta \mathrm{FeOOH}$. Journal of Magnetic and Magnetism Materials. 1984. 44: 349.

10. Pollard R.J., Cardile C.M., Lewis D.G., Brown L.J. Characterization of FeOOH Polymorphs and Ferrihydrite Using Low-Temperature, Applied-Field, Mössbauer Spectroscopy. Clay Miner. 1992. 27: 57.

11. Pankhurst, Q.A., Pollard R.J. Mossbauer-spectra of antiferromagnetic powders in applied fields. J. Phys.: Condens. Matter. 1990. 2(35): 7329.

12. Rezel D., Genin J.M.R. The substitution of chloride ions to $\mathrm{OH}^{-}$-Ions in the akaganeite beta ferric oxyhydroxide studied by Mössbauer effec. Hyperfine Interact. 1990. 57(1): 2067.

13. Dezsi I., Keszthelyi L., Kutgawczuk D., Moln B. Eissa N.A. Mössbauer Study of $\beta$ - and $\delta$-FeOOH and their Disintegration Products. Phys. Stat. Sol. 1967. 22(2): 617.

14. Braun H., Gallagher K.J. $\beta-\mathrm{Fe}_{2} \mathrm{O}_{3}$, a New Structural Form of Iron (III) Oxide. Nature Phys. Sci. 1972. $240: 13$.

15. Howe A.T., Gallagher K.J. Mössbauer studies in the colloid system $\beta-\mathrm{FeOOH}-\beta-\mathrm{Fe}_{2} \mathrm{O}_{3}$ : structures and dehydration mechanism. Journal of the Chemical Society, Faraday Transactions 1: Physical Chemistry in Condensed Phases. 1975. 71: 22 .

16. Gonzalez-Calbet J.M., Alario Franco M.A. A thermogravimetric and electron microscopy study of the decomposition of akaganeite. Thermochim. Acta. 1982. 58(1): 45.

17. Chambaere D.G., De Grave E. The $\beta-\mathrm{FeOOH}$ to $\alpha-\mathrm{Fe}_{2} \mathrm{O}_{3}$ phase transformation: Structural and magnetic phenomena. Phys. Chem. Miner. 1985. 12(3): 176.

18. Nagai N., Hosoito N., Kiyama M., Shinjo T., Takada T. The Thermal Decomposition Intermediate Product of P$\mathrm{FeO}(\mathrm{OH})$. In: Ferrites. Proc. of the International Conference (Sept.-Oct., 1980, Japan). P. 247.

19. Revo S., Alekseev A., Ivanenko E., Labi T., Boubertakh A., Hamamda S. Structure, tributechnical, and thermophysical characterristics of the fluoroplastic carbonnanotubes material. Nanoscale Res. Lett. 2014. $9(1): 1$.

20. Gin'e A. X-ray crystal. Theory and practice. (Moscow: Science, 1961).

21. Sei J.O., Cook D.C., Townsend H.E. Characterization of Iron Oxides Commonly Formed as Corrosion Products on Steel. Hyperfine Interact. 1998. 112(1-4): 59.

22. Bassi P.S., Randhawa B.S., Jamwal H.S. Mossbauer study of the thermal decomposition of iron(III) citrate pentahydrate. J. Therm. Anal. 1984. 29: 439.

23. Buchanan D.N.E. Mossbauer and spectroscopy of radiolytic photolytic effects on ferric citrate. J. Inorg. Nucl. Chem. 1970. 32(11): 3531.

24. Bernal J.D., Dasgupta D.R., Mackay A.L. The Oxides and Hydroxides of Iron and Their Structural InterRelationships. Clay Miner. 1959. 4(21): 15.

25. Chambaere D.G., De Grave E., Vanleerberghe R.L., Vandenberghe R.E. The electric field gradient at the iron sites in $\beta$-FeOOH. Hyperfine Interact. 1984. 20(4): 249.

26. Chambaere D.G., De Grave E. A study of the non-stoichiometrical halogen and water content of $\beta$-FeOOH. Phys. Stat. Sol. 1984. 83: 93.

27. Stahl K., Nielsen K., Jiang J., Lebech B., Hanson J.C., Norby P., Lanschot J. On the akaganeite crystal structure, phase transformations and possible role in post-excavational corrosion of iron artifacts. Corros. Sci. 2003. 45(11): 2563.

28. Barrero C.A., Garcia K.E., Morales A.L. Kodjikian S., Greneche J.M. New analysis of the Mössbauer spectra of akaganeite. J. Phys.: Condens. Matter. 2006. 18(29): 6827.

29. Garcia K.E., Morales A.L., Barrero C.A., Greneche J.M. Characterization of akaganeite synthesized in the presence of $\mathrm{Al}^{3+}, \mathrm{Cr}^{3+}$, and $\mathrm{Cu}^{2+}$ ions and urea. Mater. Chem. Phys. 2008. 112(1): 120.

30. Garcia K.E., Morales A.L., Barrero C.A., Arroyave C.E., Greneche J.M. Magnetic and crystal structure refinement in akaganeite nanoparticle. Physica B. 2004. 354(1-4): 187.

31. Kuzmann E., Nagy S., Vertes A. Critical Review Of Analytical Applications Of Mossbauer Spectroscopy Illustrated By Mineralogical And Geological Examples. Pure Appl. Chem. 2003. 75(6): 801.

32. Long C., Jiang L., Wei T. Yan J., Fan Z. High-performance asymmetric supercapacitors with lithium intercalation reaction using metal oxide-based composites as electrode materials. J. Mater. Chem. A. 2014. 2(39): 16678. 